\title{
Coronavirus HKU1, and Co-Infection for RSV, A Case Report in Mexico City. Pediatric patient from Belgium, December 2019
}

\author{
Ruth Sarai Aldana Vergara*, Jose Luis Patiño Galeana, Anai Ortega Espinosa, Israel Herrera \\ Flores and Genesis Betsabe Pineda Aldana
}

Hospital Ángeles Metropolitano torre Diamante tercer piso consultorio 305, Mexico

*Corresponding author: Ruth Sarai Aldana Vergara, Hospital Ángeles Metropolitano torre Diamante tercer piso consultorio 305 Tlacotalpan 59-305 delegación Cuauhtémoc, código postal 06760, Ciudad de México.

\section{ARTICLE INFO}

Received: 絊 May 25, 2020

Published: June 02, 2020

Citation: Ruth Sarai AV, Jose Luis PG, Anai Ortega E, Israel HF, Genesis Betsabe PA. Coronavirus HKU1, and Co-Infection for RSV, A Case Report in Mexico City. Pediatric patient from Belgium, December 2019. Biomed J Sci \& Tech Res 28(1)-2020. BJSTR. MS.ID.004590.

Keywords: Coronavirus; HKU1; Respiratory Syncytial Virus; Computed Tomography

\begin{abstract}
Summary
In December 2019, in the city of Wuhan, China, several cases of a new coronavirus species were detected, causing the infection called Covid-19, producing the disease SARS-CoV-2, leading to the death of countless people and consequently, the world into a pandemic. This recent coronavirus is considered the seventh strain of this species. Considering what happened in the past December 2019, the present work reports the case of an-18-month-old female patient who developed a condition in December 2019 after traveling with her parents from Belgium to Mexico City. Both, parents and child were reported as healthy. Still, upon arrival in Mexico City, the infant suddenly started with a clinical presentation of fatigue, intolerance to the environment, fever, and respiratory difficulty, which resulted in a positive viral panel for coronavirus HKU1 and RSV mixed infection after being admitted in the hospital.
\end{abstract}

Abbrevations: CAT: Computed Axial Tomography; XR: X-ray; PCR: Polymerase Chain Reaction; RSV: Respiratory Syncytial Virus; Covid-19: Coronavirus 19; SARS-CoV-2: Severe Acute Respiratory Syndrome

\section{Case Report}

This report presents the case of a one year six months old female infant who was born in Belgium without a family history of importance for the condition reported below. The patient resulted from a normally progressing pregnancy with proper prenatal care. She was born at 36.4 weeks of gestation by childbirth without complications, with adequate weight and height, without requiring advanced resuscitation maneuvers. The patient had a complete vaccination scheme for her age, according to her country of origin, and had no personal pathological history of importance. The reported condition started in December 2019, 2 days prior to her admission to the urgent care, during air travel from Belgium to Mexico. The picture was characterized by asthenia, adynamia and irritability, an increase in temperature to $37.5^{\circ} \mathrm{C}$; watery rhinorrhea; irritative and productive cough with coughing spells of 3-5 spells, with long intervals, non-cyanotic, non-dyspneic nor emetic, and with no predominance of schedule. The patient was taken to a private pediatric hospital due to initial symptoms of tachypnea, the temperature of $38.8^{\circ} \mathrm{C}$, recurrent every 6 hours, and the following vital signs: respiratory rate of 70 breaths per minute, heart rate of 184 beats per minute, blood pressure of $102 / 48 \mathrm{mmHg}$, the temperature of $38.4^{\circ} \mathrm{C}$, ambient air saturation of $72 \%$, irritability that was comforted by parents, data of severe shortness of breath at the expense of suprasternal retraction, intercostal retraction, and thoracoabdominal dissociation. The thorax presented prolonged expiration and dispersed crepitant rales, with hypoventilation areas, and the rest of the exploration without other alterations (Figure 1). 


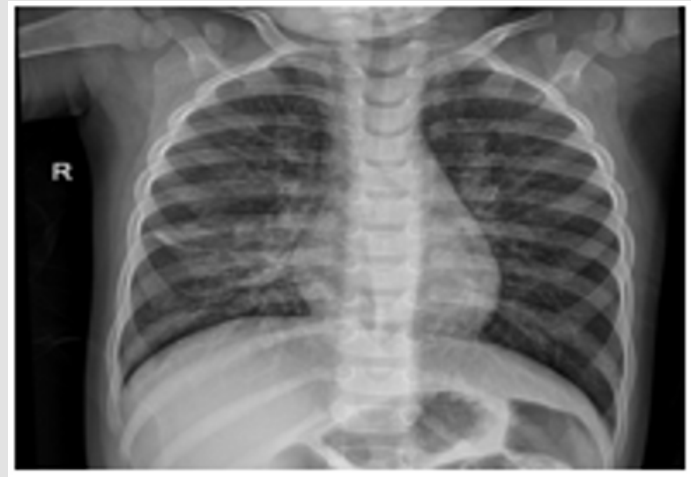

Figure (a)

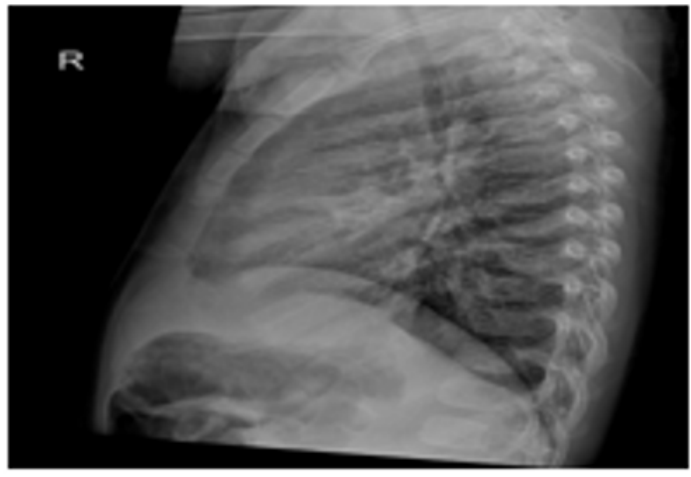

Figure (b)

Figure 1: First radiography in PA projection (a) and lateral projection (b).

a) We can see an increase in the thickness and radiopacity at the both perihilar region, in addition to identifying an incipient consolidation area in the medial segment of the middle lobe.

b) There are atelectasis bands in the middle lobe topography in addition to perihilar filling.

\section{Admission Treatment}

Influenza rapid test: negative. Hematic biometry: $\mathrm{Hb} 11.2$, HCT 34.7, MCV 70, MCH 22.7, leukocytes 17.500, neutrophils $78 \%$ (13.650), lymphocytes 18\% (3.150), monocytes 4\% (700), eosinophils 0 , basophils 0 , bands 0 , platelets 448,000, C-reactive protein: 5.12, Procalcitonin 0.91. Patient management started with a reservoir-bag mask at a rate of 10 liters/min, which improved the pulse oximetry to $98 \%$ but without improving the breathing difficulty. Thus, it was decided to admit the patient into pediatric therapy where a high-flow nasal cannula was placed at 8 liters per minute with $\mathrm{FiO}_{2}$ at $80 \%$ with dynamic management. Treatment upon admission included methylprednisolone (2 $\mathrm{mg} / \mathrm{kg} /$ day), ceftriaxone (58 mg/kg/day), clarithromycin (15 mg/kg/day), oseltamivir (6 mg/kg/day), acetaminophen (15 mg/kg/dose), and nebulizations with Combivent and budesonide. Subsequently, a nasopharyngeal swabbing sample was tested using a polymerase chain reaction test, and since it resulted positive for Coronavirus HKU1, the oseltamivir was suspended and treatment with nitazoxanide (15 mg/kg/day) was started. The patient also tested positive for respiratory syncytial virus type B (Figure $2 \& 3$ ).

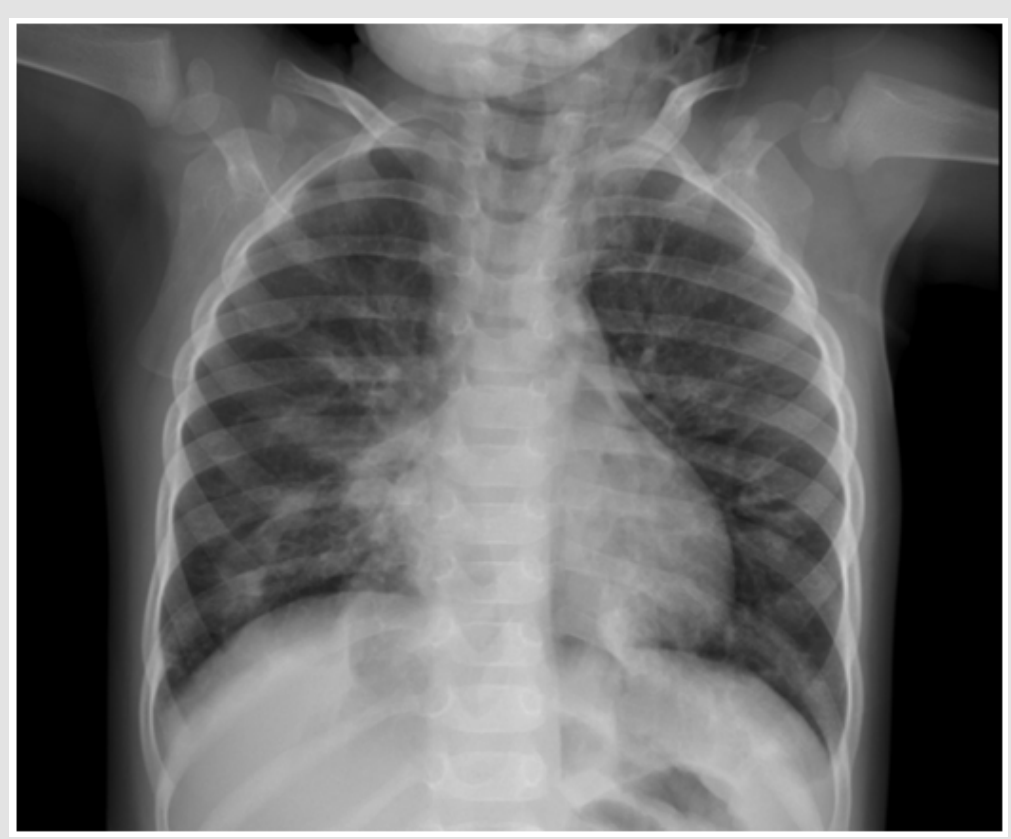

Figure 2: Radiological follow-up of 24 hours in AP chest projection, showing increase in the radiopacity of the consolidation area in the middle lobe and an increase in the size of atelectasis. 


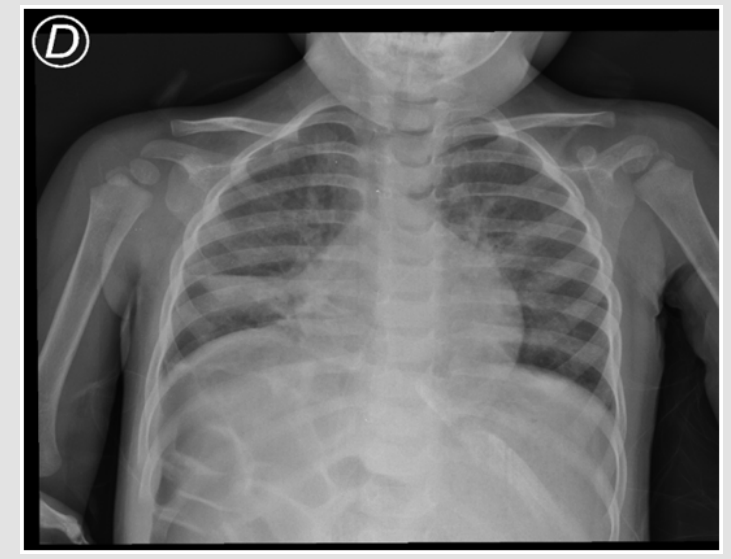

Figure 3: Last chest X-ray in AP projection, obtained on expiration, which accentuates the changes due to bilateral hilar congestion; atelectasis zones persist in the middle lobe; however, radiological improvement is evident with respect to the consolidation zone reported in previous studies.

\section{Control Treatment}

An echocardiogram showed a structurally normal heart, with no data of pulmonary hypertension. The treatment included ceftriaxone for seven days, clarithromycin for ten days, and nitazoxanide for five days. Treatment with methylprednisolone was given for five days, and treatment with prednisone $(1 \mathrm{mg} / \mathrm{kg} /$ day) was continued for seven days. Oxygen delivery devices were gradually scaled back until ambient air saturations of $92 \%$ to $98 \%$ were achieved. A thorax CT scan was requested since the condition of the patient allowed it.

\section{Tomography}

\section{Axial Cut (Figure 4)}

Single-phase tomography with pulmonary parenchyma window. Ground glass pattern is observed towards the superior lobes, showing area of healthy parenchyma toward the anterior segment of the right superior lobe.

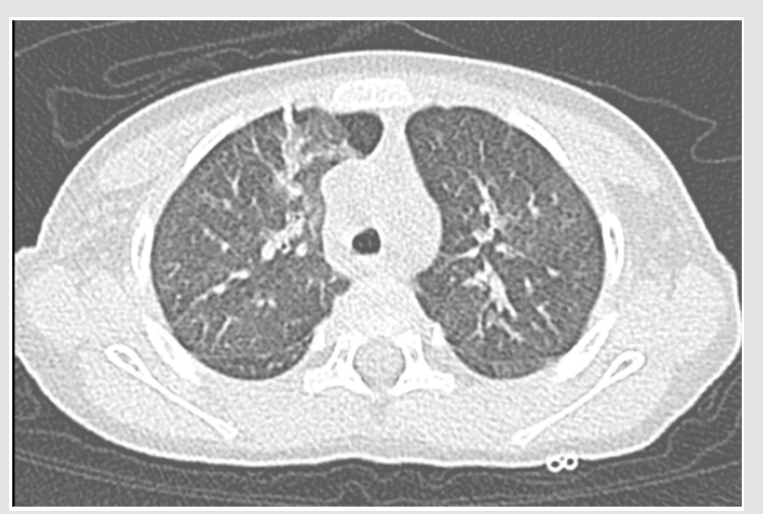

Figure 4 .

\section{CT 2}

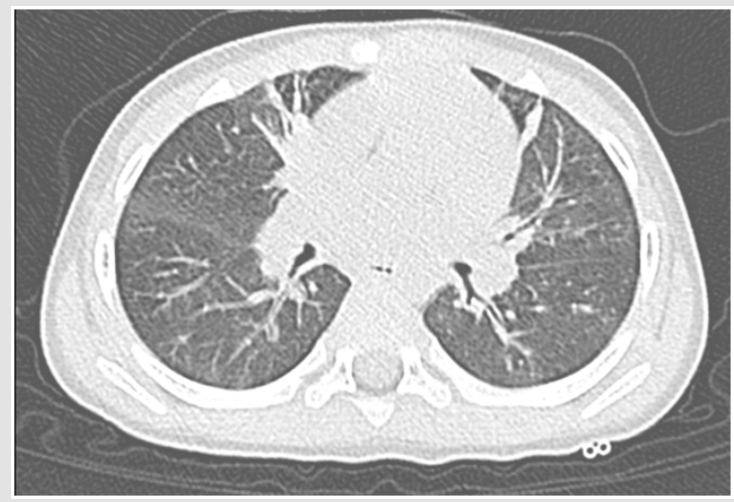

Figure 5. 
Ground glass areas persist in patches, in addition to atelectatic bands toward the topography of the medial segment of the middle lobe and the upper segment of the lingula, conditioning cylindrical bronchiectasis by traction toward the anterior región (Figure 5).

\section{Tomography 3}

\section{Axial Cut (Figure 6)}

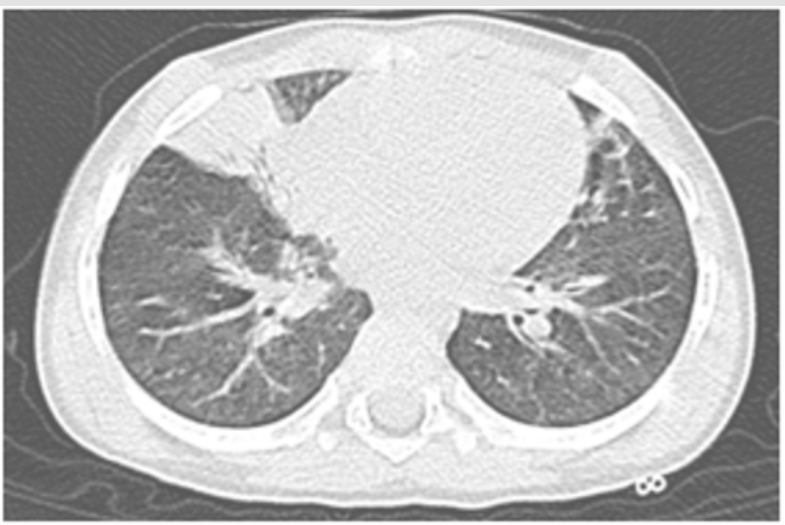

Figure (a)

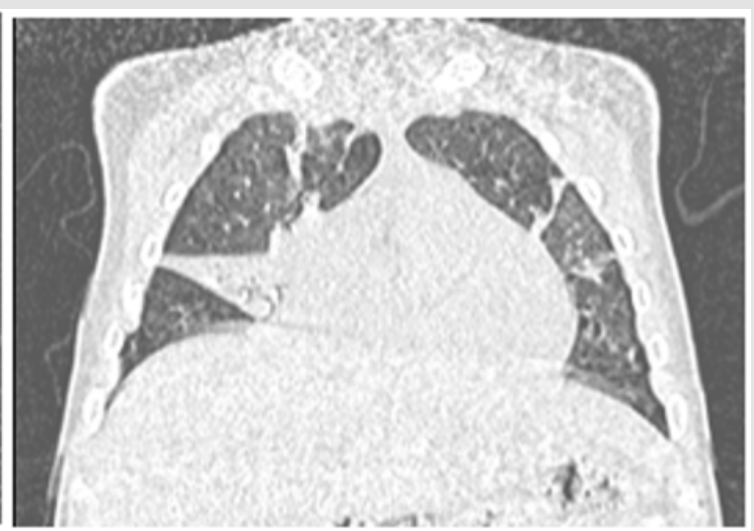

Figure (b)

Figure 6: Atelectatic area toward the medial segment of the middle lobe. Both axial and coronal cuts (a) Simple-phase axial cut in pulmonary parenchyma window and (b) Coronal cut.

\section{CT Scan}

\section{Axial Cut}

Simple tomography in pulmonary parenchyma window at the lower lobes level, showing thickening of the interlobular septal (Figure 7).

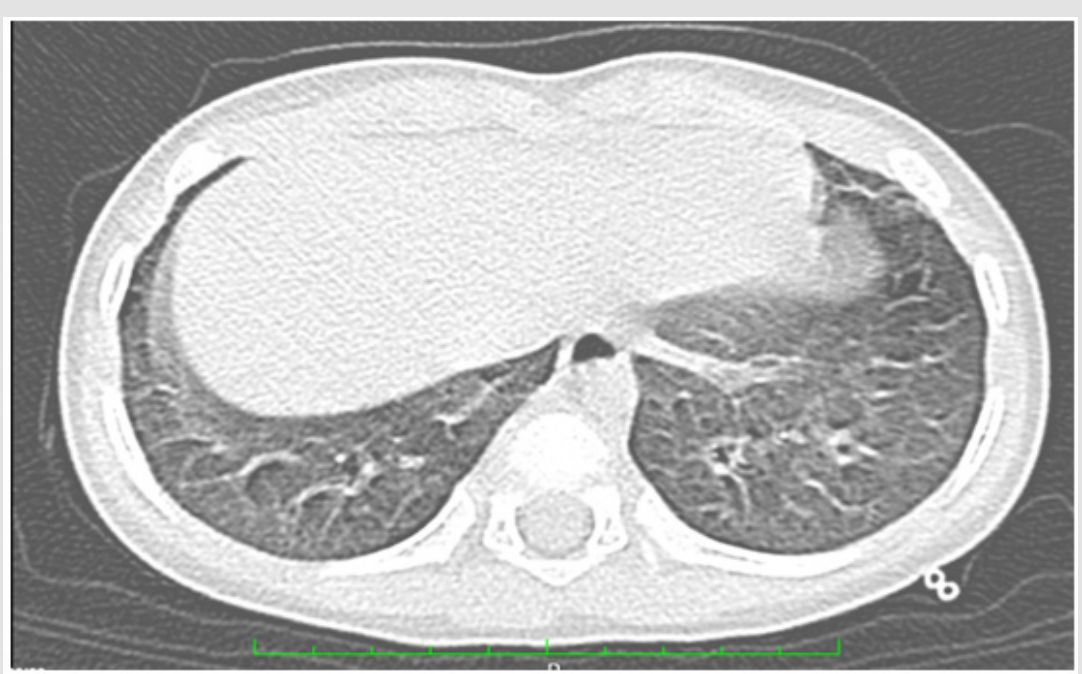

Figure 7.

Considering the CAT results, micro nebulizations with alfa dornase were added every 12 hours as well as budesonide/ formoterol through an aero chamber, causing the patient to improve. The patient was discharged after 13 days due to an adequate clinical evolution and was sent for further management to her country of origin. To the present date, the patient reports adequate growth and development without any respiratory complications.

\section{Discussion}

The coronavirus (SARS-CoV-2) CoVID-19 is to date the seventh discovered. They are described, in order of appearance as: HcoV$229 \mathrm{E}$ that was identified in 1966. HCocV-0C43 observed in 1967; both causing in humans a respiratory illness similar to the flu. The SARS-CoV discovered in November 2002, which caused an epidemic of the severe acute respiratory syndrome. HCoV-NL63 
discovered in 2003. in bronchiolitis. And the MERS-CoV that was found in 2012 in Saudi Arabia. The Coronavirus (CoV) are RNA viruses from the family coronaviridae. The coronavirus CoV-HKU1 was discovered in 2004 in a 71-year-old patient with pneumonia. The nomenclature is due to its isolation in the University of Hong Kong; apparently, the reservoirs of the virus are some mammals, and its transmission is direct to the human being [1]. This virus has been isolated in 4 to $6 \%$ of pediatric patients hospitalized with viral pneumonia and in up to $8 \%$ of ambulatory patients under 3 years old with viral pneumonia. In a retrospective review conducted in China, the CoV-HKU1 corresponded only to $0.3 \%$ of the infections caused by coronoavirus [2]; it was also reported co-infection with adenovirus, bocavirus, rhinovirus, respiratory syncytial virus, and influenza [3]. The respiratory syncytial virus type 1 and 2 is an RNA virus of the family paramixoviridae, and its prevalence in infants is $11 \%$. The transmission is well known to produce bronchiolitis through droplets of flush, but it can also develop pneumonia4, cause lower acute respiratory infection in infants, and it is the world's leading cause of hospitalization in children under two years due to bronchiolitis and viral pneumonia [4]. There are reports that state that the co-infection of CoV-HKU1 and RSV does not influence the evolution of the disease compared to patients with single viral infection [5], although clinically, they can share respiratory symptoms and be virtually indistinguishable. Therefore, the detection using molecular methods is essential to establish the epidemiological difference. The treatment of CoV-HKU1 is not yet well established, although some antiparasitic medicines are used since they have shown antiviral action.

Nitazoxanide, a broad-spectrum intestinal antiparasitic that has bactericidal properties in vitro against gram-negative, gram-positive anaerobes and against non-replicating strains of tuberculous Mycobacterium. The patient received Nitazoxanine for five days, presenting clinical improvement. It has been established in vitro that it decreases the production of pro-inflammatory cytokines in mononuclear peripheral cells and suppresses the production of IL-6.

The treatment of RSV is carried out with supportive measures. We report the case of a pediatric patient who was initially treated for a suspected diagnosis of influenza infection and bacterial aggregation. However, upon a bad evolution, the suddenness of the clinical picture, and the positive testing for co-infection with CoV-HKU1 and RSV, changes were made to her treatment resulting in a good evolution in a third level private pediatric hospital. The CoV-HKU1 and RSV viruses are more frequent in autumn and winter time [6]. The clinical symptoms for pneumonia that the patient presented are difficult to differentiate by the etiological agent since pneumonia by CoV-HKU1 and RSV can share fever, nasal symptoms, laryngitis, cough, otitis, and headache; the RSV can manifest in infants in the lower airway as bronchiolitis and viral pneumonia [7]; the HKU1 can occur as viral pneumonia in the minority of cases [2], gastrointestinal symptoms and neurological disorders such as seizures are also reported in the CoV-HKU1 [8]. The median duration of fever in HKU1 is 1.7 days, although, in association with RSV, it can increase up to 5.2 days. In the case of our patient, the median duration was three days [3]. RNA virus co-infection like the one in this clinical case may be the result of poor host response in the balance of innate immunity and adaptive immunity, the high virulence of pathogens, and the capacity to evade the host immune response. The RSV is associated with polymorphisms in genes that encode factors for innate immunity; on the other hand, coronaviruses modify the cell membrane in a way designed to increase their viral replication, so the combination of both results in more severe [9] clinical profiles. Currently, there are reports that don't show clearly if the co-infection is more severe than the single infection [10]. Chikara establishes in a retrospective analysis of pediatric patients with pneumonia due to CoV-HKU1, the presence of a co-pathogen (RSV), and the host's immune status was associated five more times with an increase in the severity of the pneumonia [11]. The diagnostic method used was filmArray®, a method for rapid detection for various pathogens, including VRS and CoV-HKU1, which obtains through a pharyngeal swabbing a very high sensitivity and specificity [12]. Levels of procalcitonin has only 0.91 , regarding the acute phase reactants, procalcitonin has significant value since viruses that stimulate macrophages by increasing alpha-interferon compared with the alpha-tumor necrosis factor that raises the procalcitonin in bacterial [2] origin. In various reports of patients with RSV infection. There is no established treatment for RSV, it is recommended maintenance treatment with oxygen therapy and fluids $[13,14$,$] in this case, with$ the co-infection the patient presented wheezing that was reverted with bronchodilators and the addition of systemic and inhaled steroids as anti-inflammatory [15] therapy, and the elevation of leukocytes with a predominance of neutrophils decides the coverage of pneumococcus since bacterial co-infections occur in 17 to $39 \%$ [16] of the patients who are admitted into pediatric intensive care.

The palivizumab as a preventive biological is indicated for patients with established risk factors such as prematurity; however, the high cost of the medication makes it difficult to access the population [17]. In recent years, several antiviral drugs have been tested as well as nuclease analogs without presenting real effectiveness in the daily use $[18,19]$. The nitazoxanide was also used, which is a broad-spectrum intestinal antiparasitic that possesses in vitro bactericidal properties against gramnegative anaerobes, gram positives and non-replicant strains of Mycobacterium tuberculosis [20]. The patient received Nitazoxanide for five days and presented clinical improvement; it has been established in vitro that it decreases the production of pro-inflammatory cytokines in peripheral mononuclear cells and suppresses the production of IL-6 [21]. The patient presented a favorable evolution and was discharged home with supplemental oxygen. 


\section{Conclusion}

HCoV-HKU1 was described in 2005 which is of interest in the present case, the reports of severe coronavirus infection in the pediatric population amount to a minimal percentage nowadays. Therefore, each country must make an effort to communicate accordingly what we see and how we treat it, to improve the statistic at global level. We think that it is essential to study each case separately from the statistics, taking into consideration the evolution of the patient, the response of their defense mechanisms, age, and sex. Also, we must base on the technological advances that are available to isolate the microorganisms, which currently allow us to make better decisions in the diagnosis and treatment for each patient.

\section{Acknowledgement}

None.

\section{Conflict of Interest}

No conflict of interest.

\section{References}

1. Corman VM, Muth D, Niemeyer D, Drosten C (2018) Hosts and Sources of Endemic Human Coronaviruses. Adv Virus Res 100:163-188.

2. Lau SKP, Woo PCY, Yip CCY, Tse H, Tsoi HW, et al.(2006) Coronavirus HKU1 and other coronavirus infections in Hong Kong. J Clin Microbiol44(6):2063-2071.

3. Zimmermann P, Curtis N (2020) Coronavirus Infections in Children Including COVID-19. Pediatr Infect Dis J39(5): 355-368.

4. Stein RT, Bont LJ, Zar H, Polack FP, Park C, et al. (2017) Respiratory syncytial virus hospitalization and mortality: Systematic review and meta-analysis. Pediatr Pulmonol52(4):556-569.

5. Gaunt ER, Hardie A, Claas ECJ, Simmonds P, Templeton KE (2010) Epidemiology and clinical presentations of the four human coronaviruses 229E, HKU1, NL63, and OC43 detected over 3 years using a novel multiplex real-time PCR method. J Clin Microbiol48(8): 2940-2947.

6. Berry M, Gamieldien J, Fielding BC (2015) Identification of new respiratory viruses in the new millennium. Viruses7(3): 996-1019.

7. Ma X, Conrad T, Alchikh M, Reiche J, Schweiger B, et al. (2018) Can we distinguish respiratory viral infections based on clinical features? A

ISSN: $2574-1241$

DOI: $10.26717 /$ BJSTR.2020.28.004590

Ruth Sarai Aldana Vergara. Biomed J Sci \& Tech Res

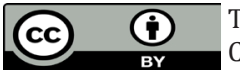

This work is licensed under Creative Commons Attribution 4.0 License

Submission Link: https://biomedres.us/submit-manuscript.php prospective pediatric cohort compared to systematic literature review. Rev Med Virol28(5): 1-12.

8. Geller C, Varbanov M, Duval RE (2012) Human coronaviruses: Insights into environmental resistance and its influence on the development of new antiseptic strategies. Viruses 4(11): 3044-3068.

9. Kikkert M (2020) Innate Immune Evasion by Human Respiratory RNA Viruses. J Innate Immun12(1): 4-20.

10. Debiaggi M, Canducci F, Ceresola ER, Clementi M (2012) The role of infections and co-infections with newly identified and emerging respiratory viruses in children. Virol J 9: 1-18.

11. Ogimi C, Englund JA, Bradford MC, Qin X, Boeckh M, et al. (2019) Characteristics and outcomes of coronavirus infection in children: The role of viral factors and an immunocompromised state. J Pediatric Infect Dis Soc8(1): 21-28.

12. Leber AL, Everhart K, Daly JA, Hopper A, Harrington A, et al. (2018) Multicenter evaluation of BioFireFilmArray respiratory panel 2 for detection of viruses and bacteria in nasopharyngeal swab samples. J Clin Microbiol56(6): 1-29.

13. Xing Y, Proesmans M (2019) New therapies for acute RSV infections: where are we? Eur J Pediatr.

14. Newns GH (1944) Bronchiolitis in Children. J R Soc Med37(10): 580-585.

15. Massie RJ, Robertson CF, Berkowitz RG (2000) Long-term effects of prednisolone in the acute phase of bronchiolitis caused by respiratory syncytial virus. Pediatr Pulmonol30(2): 92-96.

16. Thorburn K, Riordan A (2012) Pulmonary bacterial co-infection in infants and children with viral respiratory infection. Expert Rev Anti Infect Ther 10(8): 909-916.

17. Behzadi MA, Leyva-Grado VH (2019) Overview of current therapeutics and novel candidates against influenza, respiratory syncytial virus, and Middle East respiratory syndrome coronavirus infections. Front Microbiol10(JUN).

18. Jordan PC, Stevens SK, Deval J (2018) Nucleosides for the treatment of respiratory RNA virus infections. Antivir Chem Chemother26: 1-19.

19. Beigel JH, Nam HH, Adams PL, Krafft A, Ince WL, et al. (2019) Advances in respiratory virus therapeutics - A meeting report from the 6th isirv Antiviral Group conference. Antiviral Res167(March): 45-67.

20. Rossignol JF (2014) Nitazoxanide: A first-in-class broad-spectrum antiviral agent. Antiviral Res110(August): 94-103.

21. Rossignol JF (2016) Nitazoxanide, a new drug candidate for the treatment of Middle East respiratory syndrome coronavirus. J Infect Public Health9(3): 227-230.

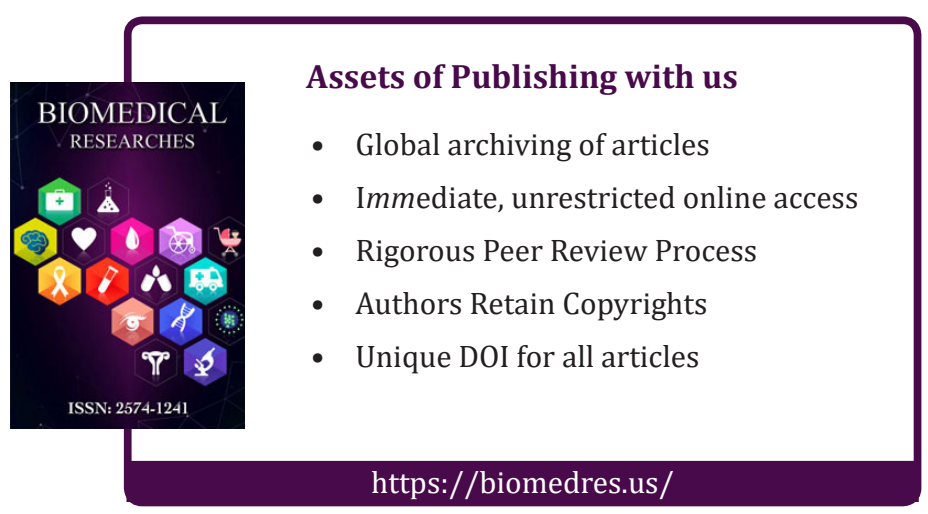

